\title{
QSAR studies combined with DFT-calculations and Molecular docking of polyamine-sensitive inhibitors of the NMDA receptor
}

\author{
Mohamed Mazigh, Charif El'mbarki, Hanine Hadni * and Menana Elhallaoui \\ Engineering Materials, Modeling and Environmental Laboratory, Faculty of Sciences of Dhar Elmehraz, Sidi \\ Mohammed Ben Abdellah University, B.P. 1796, Atlas, Fes, Morocco
}

\begin{abstract}
A quantitative structure-activity relationship (QSAR) was carried out to analyze inhibitory activity of 35 compounds, new polyamine-sensitive inhibitors of the NMDA receptor, using multiple linear regression (MLR), artificial neural networks (NN), and the molecular descriptors were calculated using DFT method. This study shows that the compounds' activity correlates reasonably well with six selected descriptors by MLR method. The correlation coefficients calculated by MLR and after that by NN, $\mathbf{R}=\mathbf{0 . 8 7 8}$ and $\mathbf{R}=\mathbf{0 . 9 7 8}$ respectively, are relatively kind to evaluate the proposed quantitative model, and to predict activity for new polyamine-sensitive inhibitors of the NMDA receptor. The test of the performance of the NN model, using a cross-validation method with a leave-one-out procedure (LOO) shows that the predictive power of this model is relevant $(\mathbf{R = 0 . 9 6 6})$. The constitutional molecular descriptors (nN and $\mathbf{n H B D}$ ) have the most significant impact in the formulation of the QSAR model. The molecular docking investigations exploring the influence of the structural differences in the interaction potency demonstrate that the number of $\mathrm{N}$ atoms expressed by multiple hydrogen bonds helps the ligand to be fixed to NR2B subtype of NMDA receptor.
\end{abstract}

Keywords: QSAR; MLR; Neural Network, Cross Validation, NMDA receptor, Molecular docking.

\section{Introduction}

$\mathrm{N}$-methyl-D-aspartate receptors (NMDARs) are ionotropic glutamate receptors that play important roles in general neurotransmission ${ }^{1}$. This glutamate receptor subtype is linked to an ion channel with high $\mathrm{Ca}^{2+}$ ion permeability, its conductance critically depending on partial depolarization ${ }^{2}$. By virtue of these properties, NMDARs play a crucial role in synaptic plasticity, but also are at risk to convey a deadly threat to neurons, since prolonged NMDARs stimulation as it may occur in stroke, epilepsy or neurological conditions as Chorea Huntington runs the risk of $\mathrm{Ca}^{2+}$ overload ${ }^{3}$. Polyamines exhibit their NMDA receptor modulatory activity based on several key structural features, including the number of amino- groups, distance between the amino-groups, lipophilic or hydrophilic domains, and charge ${ }^{4}$.

Among the attempts to discover neuroprotective agents, one is directed towards the search of new polyamine-sensitive inhibitors of the NMDA receptor. The discovery that the spermine sensitivity of $\left[{ }^{3} \mathrm{H}\right] \mathrm{MK}-801$ binding inhibition is responsive to subtle changes in inhibitor structure represents a promising target for pharmaceutical research 5 . Quantitative structure-activity relationships (QSAR) studies have acquired an essential position within

*Corresponding author: Hanine Hadni

Email address: hadni.hanine@yahoo.fr

DOI: http://dx.doi.org/10.13171/mjc93190924930hh modern chemistry. In QSAR analysis, one or more molecular descriptors are related to the molecular activity using statistical analysis. The main objective of this analysis is the creation of statistical models through which it is possible to predict the biological activity of novel compounds that have not been tested yet. Also, a variety of statistical methodologies applicable to chemometric analysis exists, like Multiple Linear Regression (MLR), and different types of Artificial Neural Networks (NN) ${ }^{6}$. These techniques can effectively be used to establish a correlation model between the molecular structures (molecular descriptors) and the associated properties. So in this work, in the first part, we attempted to establish a quantitative structure-activity relationship for new polyamine-sensitive inhibitors of the NMDA receptor by studying a selected series of 35 5-(4-aminobutyl)-2-thiophene-ethylamine derivatives. We accordingly propose a quantitative model, and we tried to interpret the activity of the compounds relying on the multivariate statistical analyses. The multiple regression analysis (MLR) had served to predict activities and to select the descriptors used as the input parameters for a backpropagation network (NN). To test the performance of this model, we have used the cross-validation method. In the second part we attempted to explore the nature of the 
interactions established between inhibitors and the receptor by using the molecular docking method.

\section{Material and Methods}

2.1. Experimental Data

In this work, a series of 35 5-(4-aminobutyl)-2thiophene-octylamine derivatives that are submitted to QSAR techniques, are sketched in Table 1 with their observed activities. The Biological activity values are converted into a logarithm scale.

Table 1. The chemical structures of the 35 studied compounds, with their observed activities ( $\mathrm{pIC}_{50}$ obs) ${ }^{5}$, and the values of predicted $\mathrm{pIC}_{50}$ by $\mathrm{MLR}\left(\mathrm{pIC}_{50} \mathrm{MLR}\right), \mathrm{NN}\left(\mathrm{pIC}_{50} \mathrm{NN}\right)$ and $\mathrm{CV}\left(\mathrm{pIC}_{50} \mathrm{CV}\right)$.

\begin{tabular}{|c|c|c|c|c|c|}
\hline $\mathbf{N}$ & Structure of compound & $\mathrm{pIC}_{50} \mathrm{Obs}$ & $\mathrm{pIC}_{50}$ MLR & $\mathrm{pIC}_{50} \mathrm{NN}$ & $\mathrm{pIC}_{50} \mathrm{CV}$ \\
\hline \multirow[t]{2}{*}{1} & & & & & \\
\hline & & 0.2676 & -0.2406 & 0.2655 & -0.1573 \\
\hline 2 & & & & & \\
\hline 3 & & $2=520$ & 26102 & $2=2020$ & \\
\hline 4 & & -2.1156 & -1.5249 & -2.1141 & -2.0453 \\
\hline 5 & & & & & \\
\hline 6 & & & & & \\
\hline 7 & & & & & \\
\hline \multirow[t]{2}{*}{8} & & & & & \\
\hline & & -1.1818 & -1.1443 & -1.1816 & -1.2013 \\
\hline 9 & & 0.2006 & 0.1354 & -0.2085 & $\mathbf{0 . 1 3 8 5}$ \\
\hline \multirow[t]{2}{*}{10} & & & & & \\
\hline & & -0.0530 & -0.1424 & -0.0529 & $-\mathbf{0 . 0 3 1 7}$ \\
\hline \multirow[t]{2}{*}{11} & & & & & \\
\hline & & -0.1832 & -0.1587 & -0.2099 & -0.1935 \\
\hline
\end{tabular}




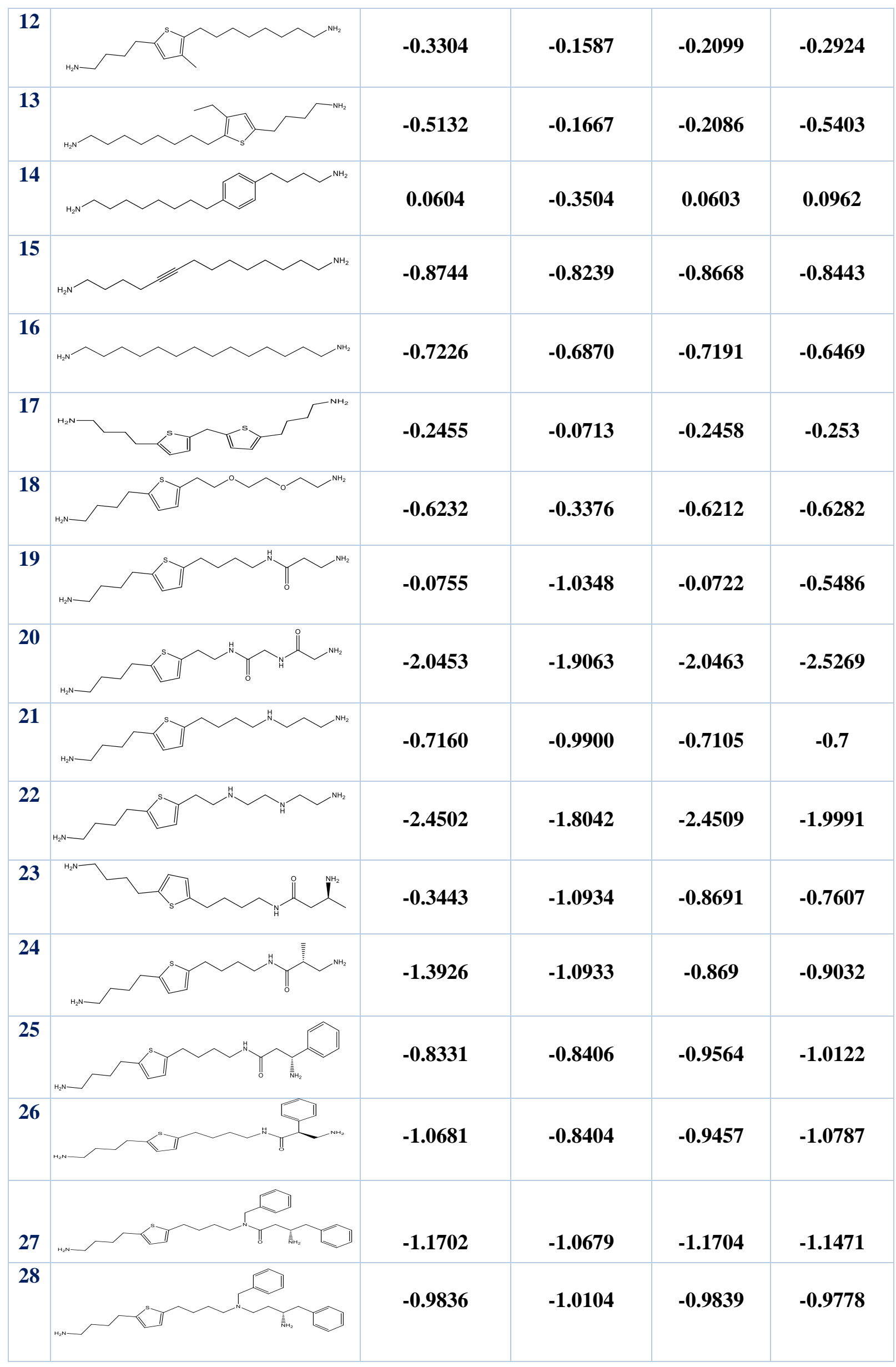




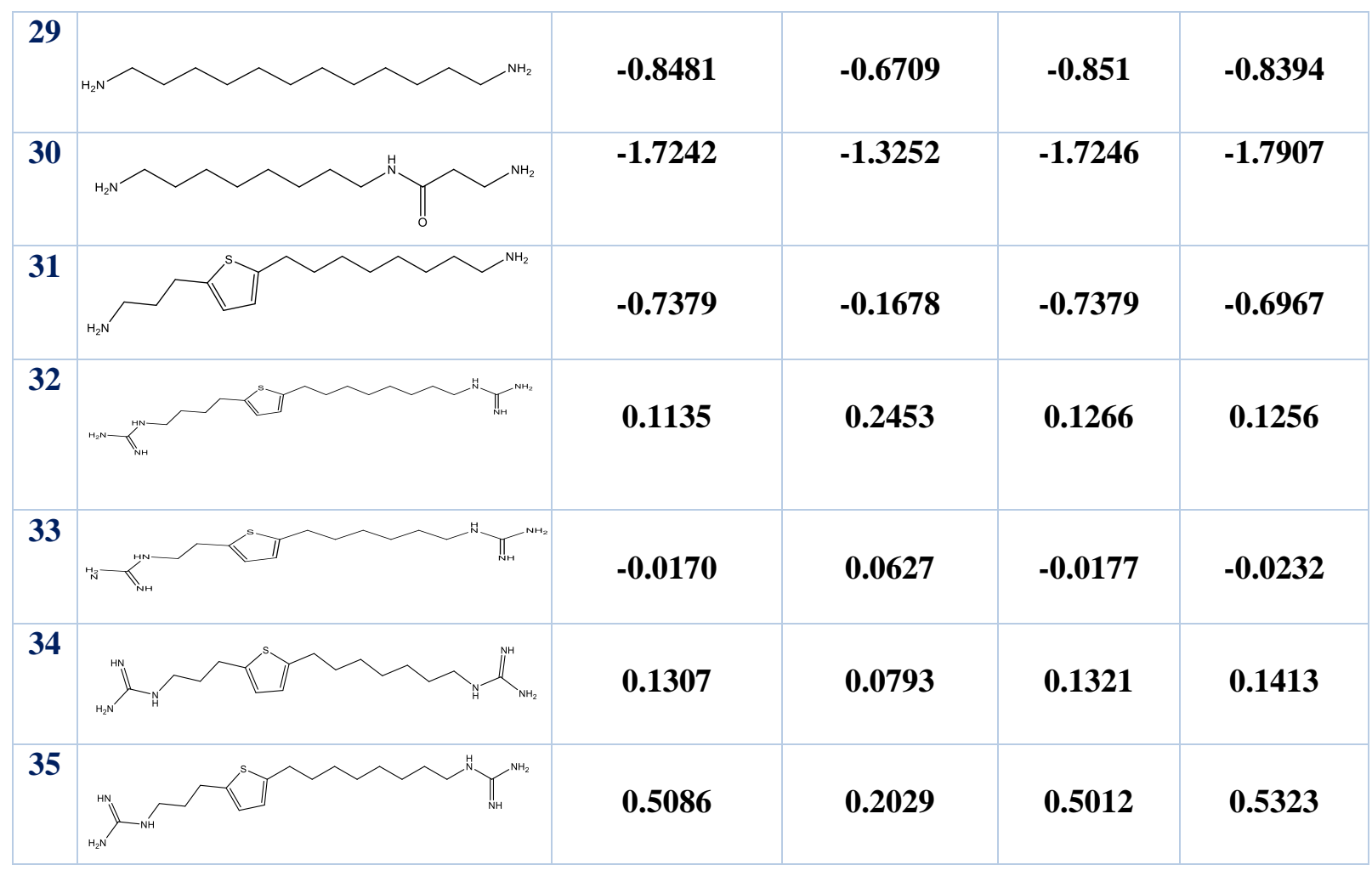

\subsection{Molecular descriptors}

To derive QSAR models, an appropriate representation of the chemical structure is necessary. For this purpose, descriptors of the structure are commonly used. These descriptors are generally understood as being any term, index or parameter conveying structure information. In order to model and predict the activities predicted with accuracy, 19 descriptors (Table 2) including electronic, constitutional, steric, and topological parameters were taken into account as inputs to the model building.

Table 2. The calculated descriptors used in this study.

\begin{tabular}{|c|c|c|}
\hline Descriptors & Symbol & Abbreviation \\
\hline Electronic & $\begin{array}{l}\text { Lowest Unoccupied Molecular Orbital } \\
\text { Electron affinity } \\
\text { Total energy } \\
\text { Softness } \\
\text { Electrophilicity } \\
\text { Dipole moment }\end{array}$ & $\begin{array}{l}\text { LUMO } \\
\mathbf{I} \\
\mathbf{E} \\
\mathbf{S} \\
\mathbf{W} \\
\boldsymbol{\mu}\end{array}$ \\
\hline Topological & $\begin{array}{l}\text { Sum of Degrees } \\
\text { Sum of Valence Degrees } \\
\text { Shape Attribute } \\
\text { Total Connectivity }\end{array}$ & $\begin{array}{l}\text { SD } \\
\text { SVD } \\
\text { SA } \\
\text { TC }\end{array}$ \\
\hline Steric & $\begin{array}{l}\text { Molecular volume } \\
\text { Surface Tension } \\
\text { Molar Refractivity } \\
\text { Molecular Weight } \\
\text { Partition coefficient (octanol water) } \\
\text { Ovality }\end{array}$ & $\begin{array}{l}\text { MV } \\
\text { ST } \\
\text { MR } \\
\text { MW } \\
\text { ClogP } \\
\text { O }\end{array}$ \\
\hline Constitutional & $\begin{array}{l}\text { Number of azote atoms } \\
\text { Number of HBond Donors } \\
\text { Number of HBond Acceptors }\end{array}$ & $\begin{array}{l}\text { nN } \\
\text { nHBD } \\
\text { nHBA }\end{array}$ \\
\hline
\end{tabular}

In this work, electronic descriptors are calculated with the aid of Gaussian 03 quantum chemistry package ${ }^{7}$, the structures of the molecules are optimized by the
DFT method ${ }^{8}$, by employing Becke's threeparameter hybrid functional (B3LYP $)^{9}$, with a 6$31 \mathrm{G}$ basis set. For topological, steric and 
constitutional descriptors, initial geometry optimization was carried out with a molecular mechanic method using the MM2 force fields with the aid of ChemBio3D 13.0 and ACD/ChemSketch program ${ }^{10}$.

\subsection{Methods}

\subsubsection{Multiple Linear Regression (MLR)}

The multiple linear regression statistic technique is used to study the relationship between one dependent variable and several independent variables. It is a mathematical technique that minimizes the differences between actual and predicted values. The multiple linear regression model (MLR) was generated using the software SYSTAT, version 13, to predict inhibitory activity $\mathrm{pIC}_{50}$. It has also served to select the descriptors used as the input parameters for a backpropagation network (NN). Statistical properties of the proposed equation, including correlation coefficient (R), adjusted squared multiple $\left(\mathrm{R}^{2}\right.$ adj $)$, and standard error of estimate $(\mathrm{S})$, probability values (p-value) of each descriptor, and Fischer statistic or variance ratio $(\mathrm{F})$ are regarded as indicators of the performance of the model.

\subsubsection{Neural Network (NN)}

$\mathrm{NN}$, which mimics the human brain process information, is useful in detecting a complicated nonlinear relationship between a set of inputs and outputs. Briefly, the general structure of $\mathrm{NN}$ has one input layer, one or more hidden layers and one output layer 11. Each layer has some units corresponding to neurons. The units in neighboring layers are fully interconnected with links corresponding to synapses. The MLR Selected descriptors represent the neurons of the input layer, and $\mathrm{pIC}_{50}$ values represent the output neurons. Although there are neither theoretical nor empirical rules to determinate the number of hidden layers, one hidden layer seems to be sufficient in the most chemical applications of $\mathrm{NN}^{12}$, some authors have proposed a parameter $\rho$ leading to determine the number of hidden neurons, which play a significant role to determine the best $\mathrm{NN}$ architecture. It's defined as follows:

$$
\rho=\frac{\text { Number of data points in the training set }}{\text { Sum of the number of connections in the NN }}
$$

Four hidden neurons were taken to maintain $\rho$

between 1 and $3(1<\rho<3)^{13}$. So, the NN architecture is as shown in Figure $1(6-4-1)$ :

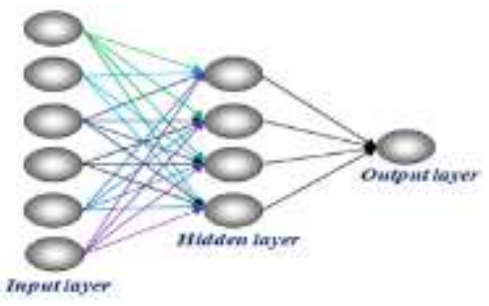

Figure 1. The NN architecture used in this work

\subsubsection{Cross-Validation}

Cross-validation is a popular technique used to explore the reliability of statistical models. In this aspect, the well-known «leave-one-out» (LOO) approach in which several models were developed with one sample ignored each time is used in this work ${ }^{14}$. A CV model is created from the remaining data points using the descriptions from of the original model and tested on the removed molecules for its ability to correctly predict the activity.

\subsubsection{Molecular docking}

The molecular docking was generated using the AutoDock Tools software ${ }^{13}$. The geometries of ligands are built and optimized using a molecular mechanic method using the MM2 force fields with the aid of chemBio3D 13.0 software and the docked conformations were viewed using Discovery Studio 4.1 software package ${ }^{14}$. The receptor NMDA (RN2B subtype ${ }^{15}$ ) was retrieved from the protein data bank (PDB code: 3JPY, resolution: $3.21 \AA$ ). The docking process parameters are adjusted as follows: The Grid size set is $100 \times 100 \times 100$ related to $x y z$ dimension, with a grid spacing of $0,400 \AA$, the center grid box is about $23 \AA,-25 \AA, 17 \AA$, the number of Genetic Algorithm runs $=5$, the population size $=150$, the maximum number of evaluations $=2.5$ million, the maximum number of generations $=27000$ parameters . The binding mode analysis is performed with the complex (ligand + receptor) having the lowest energy.

\section{Results and Discussions}

\subsection{Multiple Linear Regression (MLR)}

The data set constituted of the 35 molecules, and the 19 descriptors is submitted to a progressive multiple regression analysis in order to propose an MLR model. This method used the coefficients $\mathrm{R}, \mathrm{R}^{2}$, and the $\mathrm{t}$-values to select the best regression performance. The best results were obtained with 6 descriptors SVD, nN, MW, E, MV, nHBD forming the following equation:

$$
\begin{gathered}
\mathrm{p} \mathrm{IC}_{50}=2.258+0.234 \mathrm{MW}+0.014 \mathrm{E}+0.747 \mathrm{nHBD}-0.126 \mathrm{MV}-1.878 \mathrm{nN}-0.334 \mathrm{SVD}(1) \\
\mathrm{R}=0.878 \quad \mathrm{R}^{2}=0.771 \quad \mathrm{~S}=\mathbf{0 . 3 2 8} \quad \mathrm{N}=35
\end{gathered}
$$


The contributions of selected descriptors are

illustrated in Figure 2.

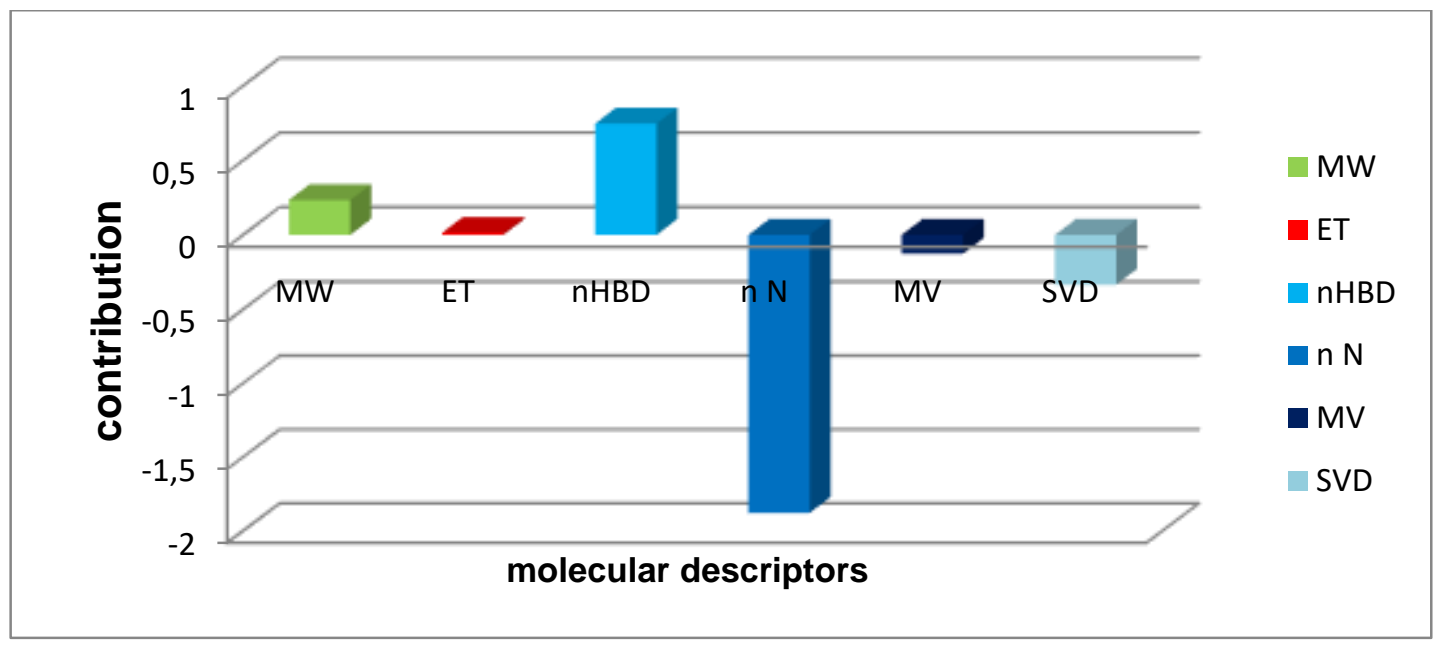

Figure 2. Contributions of selected descriptors

The predicted $\mathrm{pIC}_{50}\left(\mathrm{pIC}_{50} \mathrm{MLR}\right)$ calculated from equation (1), and observed $\mathrm{pIC}_{50}$ values ( $\mathrm{pIC}_{50}$ obs) are presented in Table 1 . The selected descriptors with their regression coefficients and statistical characteristics: t-values, standard errors and p-values are shown in Table 3. The correlation of predicted activities $\mathrm{pIC}_{50}$ MLR and observed ones $\mathrm{pIC}_{50}$ obs is illustrated in Figure 3.

Table 3. The selected descriptors with their regression coefficients and statistical characteristics: t-values, standard errors and p-values.

\begin{tabular}{|l|c|c|c|c|}
\hline Descriptor & Coefficient & Standard Error & t-value & p-Value \\
\hline CONSTANT & 2.258 & 0.709 & 3.184 & 0.004 \\
\hline WM & 0.234 & 0.029 & 8.192 & 0.000 \\
\hline E & 0.014 & 0.002 & 7.488 & 0.000 \\
\hline nHBD & 0.747 & 0.183 & 4.069 & 0.000 \\
\hline MV & -0.126 & 0.015 & -8.236 & 0.000 \\
\hline nN & -1.878 & 0.247 & -7.599 & 0.000 \\
\hline SVD & -0.334 & 0.042 & -7.879 & 0.000 \\
\hline
\end{tabular}

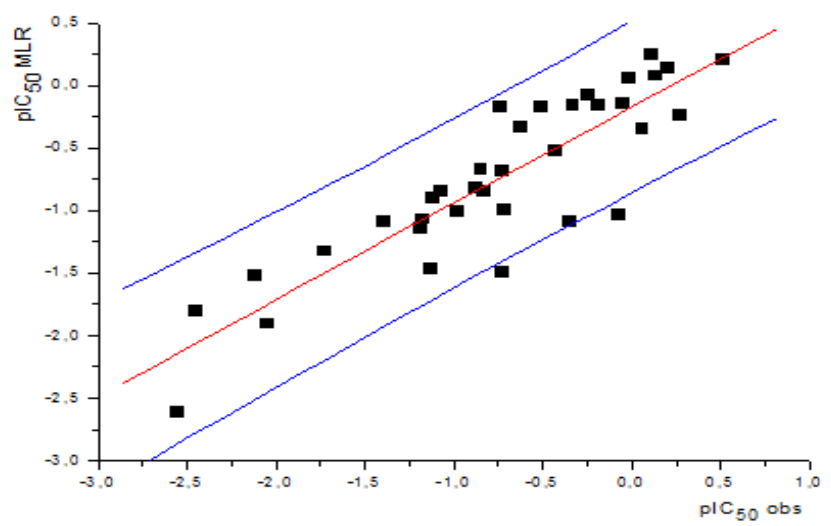

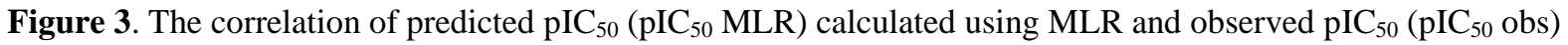

The correlation coefficient is $\mathbf{R}=\mathbf{0 . 8 7 8}$, the square $\mathbf{R}^{2}$ $=\mathbf{0 . 7 7 0}$, and the standard error $\mathbf{S}=\mathbf{0 . 3 2 8}$. These values are relevant to evaluate the quantitative model. The Constitutional descriptors; Number of azote atoms (nN) and Number of H Bond Donors (nHBD) are the most important factors in the establishment of the QSAR model of 5-(4-aminobutyl)-2-thiopheneoctylamine derivatives. at the same time, we note that topological and electronic descriptors seem to have a non-negligible impact on the QSAR model. The selected descriptors by MLR were, therefore, used as the input parameters in $\mathrm{NN}$.

\subsection{Neural Network (NN)}

In this work, we submitted the training set to a neural network with three layers and complete connections between neurons. The input layer is constituted by the 6 descriptors proposed in equation (1), the hidden 
layer is selected with 4 tansig neurons, and the output layer is a linear neuron. So, the best architecture is: 64-1. Values of $\mathrm{pIC}_{50}$ calculated with 6-4-1 network $\left(\mathrm{pIC}_{50} \mathrm{NN}\right)$ are given in Table 1 , and the correlation obtained is illustrated in Figure 4. The correlation coefficient is $\mathbf{R}=\mathbf{0 . 9 7 8}$, the square $\mathbf{R}^{2}=\mathbf{0 . 9 5 6}$.

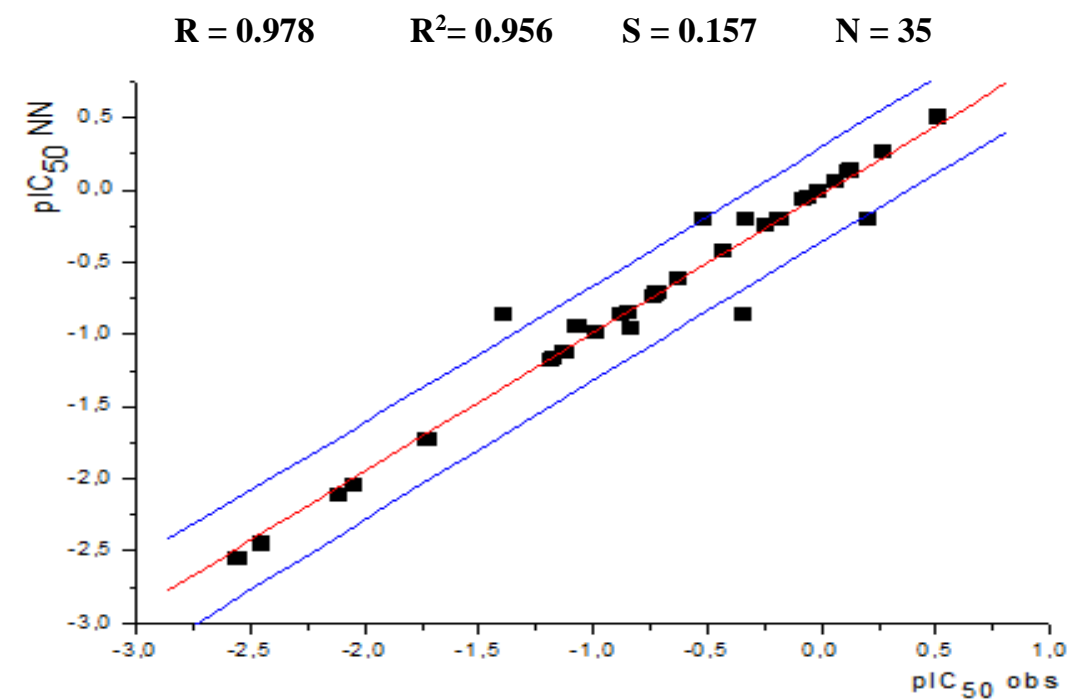

Figure 4. The correlation of predicted $\mathrm{pIC}_{50}\left(\mathrm{pIC}_{50} \mathrm{NN}\right)$ Calculated using the Neural Network and observed $\mathrm{pIC}_{50}$ ( $\mathrm{pIC}_{50}$ obs)

\subsection{Cross-validation}

We have used the cross-validation method with «leave one out» procedure, for the aim of testing the performance of the NN and the validity of the choice of our descriptors. The calculated $\mathrm{pIC}_{50}$ values $\left(\mathrm{pIC}_{50}\right.$ $\mathrm{CV})$ are given in Table 1, and the correlation with $\mathrm{pIC}_{50}$ obs is illustrated in Figure 5.

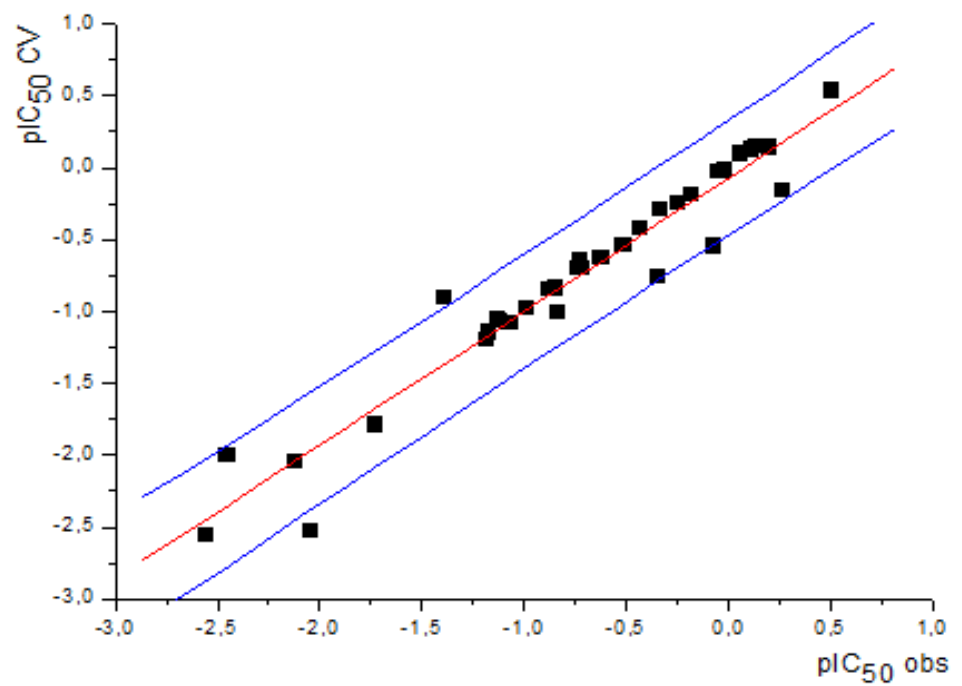

Figure 5. The correlation of predicted $\mathrm{pIC}_{50}\left(\mathrm{pIC}_{50} \mathrm{CV}\right)$ Calculated using the cross-validation method with 'leave one out' procedure and observed $\mathrm{PIC}_{50}$ ( $\mathrm{pIC} \mathrm{C}_{50}$ obs)

$$
\mathbf{R}=\mathbf{0 . 9 6 6} \quad \mathrm{R}^{2}=\mathbf{0 . 9 3 3} \quad \mathrm{S}=\mathbf{0 . 1 9 2} \quad \mathrm{N}=35
$$

The cross-validation coefficient is $\mathbf{R}=\mathbf{0 . 9 6 6}$ and the square $\mathbf{R}^{\mathbf{2}}=\mathbf{0 . 9 3 3}$.

Best results obtained with the cross-validation (The cross-validation coefficient $\mathbf{R}=\mathbf{0 . 9 6 6}$, and the square $\mathbf{R}^{\mathbf{2}}=\mathbf{0 . 9 3 3}$ ) show that the model proposed in this paper can predict activity with high performance and that the selected descriptors are pertinent.

\subsection{Molecular docking}

Modeling the interaction of a drug with its receptor is a complex problem; many forces are involved in the intermolecular association: hydrophobic, dispersion, or Van der Waals, hydrogen bonding, and electrostatic. The dominant force binding appears to be hydrophobic interactions, but the specificity of the binding appears to be controlled by hydrogen bonding and electrostatic interactions ${ }^{16}$. So in this work, Molecular docking is used to predict the binding mode 
of ligands within NMDA receptor sites. The 5-(4aminobutyl)-2-thiophene-ethylamine shown in Figure 6 , coded as compound 1 in Table 1 , and considered as the most active molecule in the studied series, is chosen as a reference in molecular docking of the rest of its derivatives. So in this study, five compounds 1 , $2,14,15,35$, were docked to NMDA receptor (NR2B subtype) to explore the influence of the structural difference in the interaction potency.

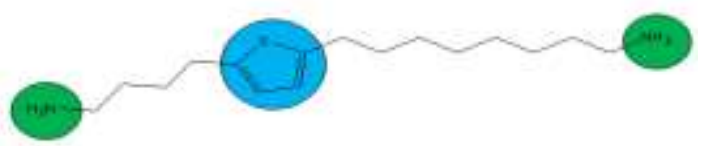

Figure 6. Chemical structure of compound $\mathbf{1}$

Figure 7 illustrates in 2D and 3D, the interactions

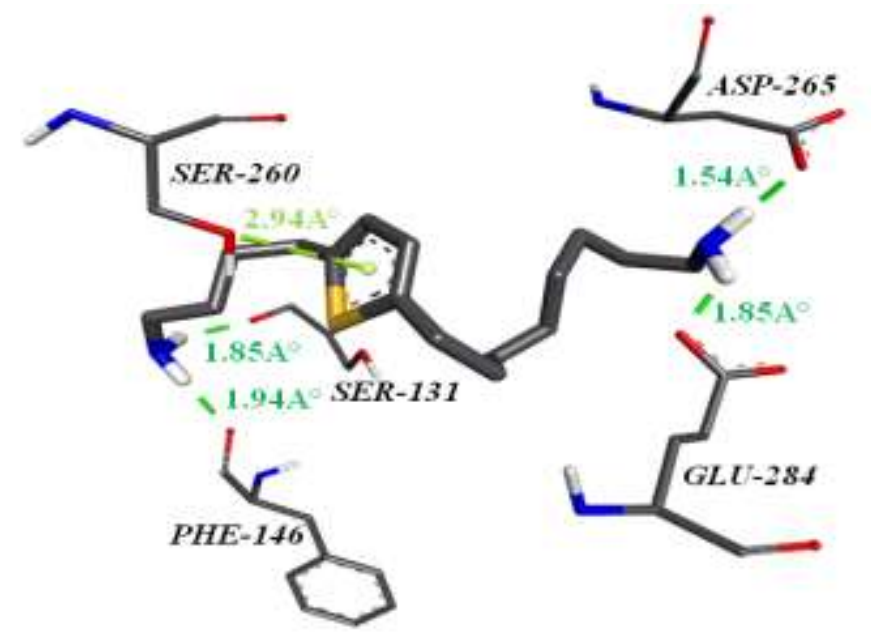

revealed with the docking of compound 1 to NMDA receptor NR2B subtype.

Figure 7. 2D and 3D maps of Molecular docking of compound 1 in the NMDA receptor binding site NR2B

As it is shown in Figure 7, compound 1 established four hydrogen bonding throughout its two amino groups with important residual sites SER-131 $\left(\mathbf{1 . 8 5} \mathbf{A}^{\circ}\right), \mathrm{PHE}-146\left(\mathbf{1 . 9 4 A}^{\circ}\right)$, GLU-284 $\left(\mathbf{1 . 8 5}^{\circ}\right)$, and
ASP-265 $\left(\mathbf{1 . 5 4 A}^{\circ}\right)$. Further, the thiophene ring forms a $\pi$-Lone pair interaction with SER-260 residue.

The interactions generated from the docking of compound 14 with NR2B are illustrated in Figure 8.
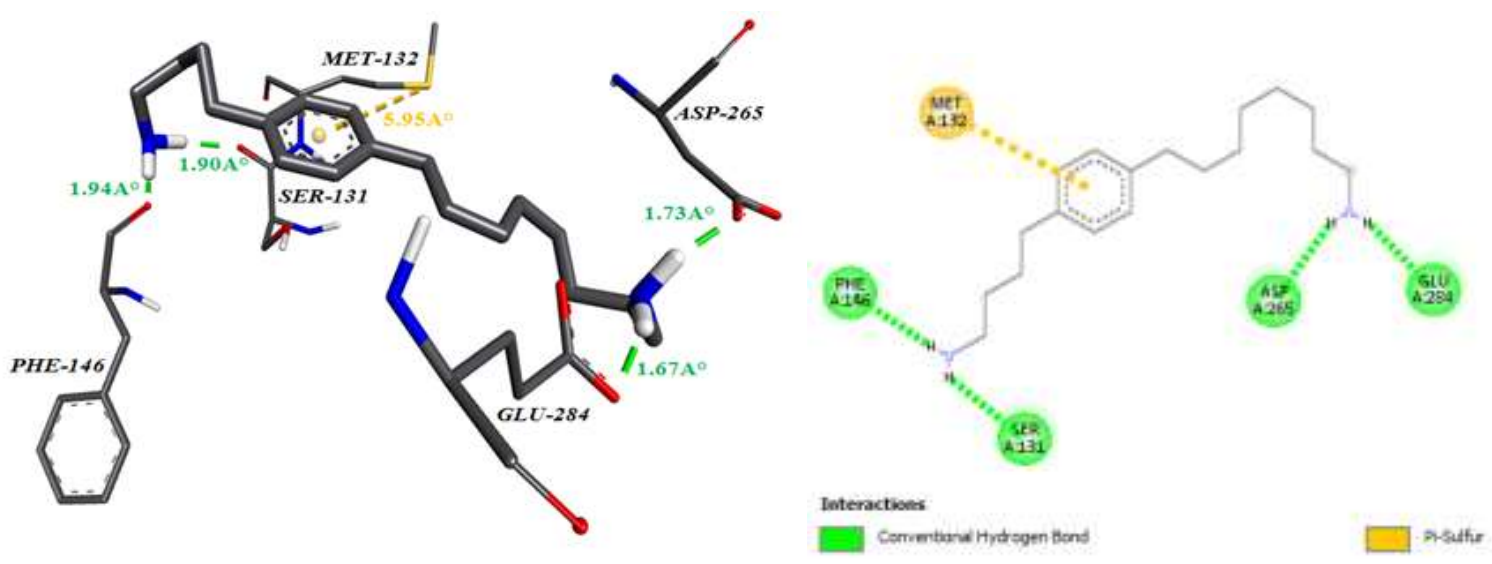

Figure 8. 2D and 3D maps of Molecular docking of compound 14 with NMDA receptor NR2B subtype.

The compound 14 forms the same interactions as shown with compound 1, except the phenyl ring that forms $\pi$-sulfur interaction with MET-132 (5.95. $\left.{ }^{\circ}\right)$ instead of $\pi$-lone pair with SER-260 $\left(\mathbf{2 . 9 4 A}^{\circ}\right)$ in the case of compound 1 . We note that compound 14 is less active than compound 1, which could be explained by the difference of distances of their aromatic groups' interactions.
The docking of compound 15 illustrated in Figure 9 shows the same interactions as for compounds 1 and 14 ; however, we did not observe any $\pi$ interaction, which could be the cause of the decrease of its activity. 


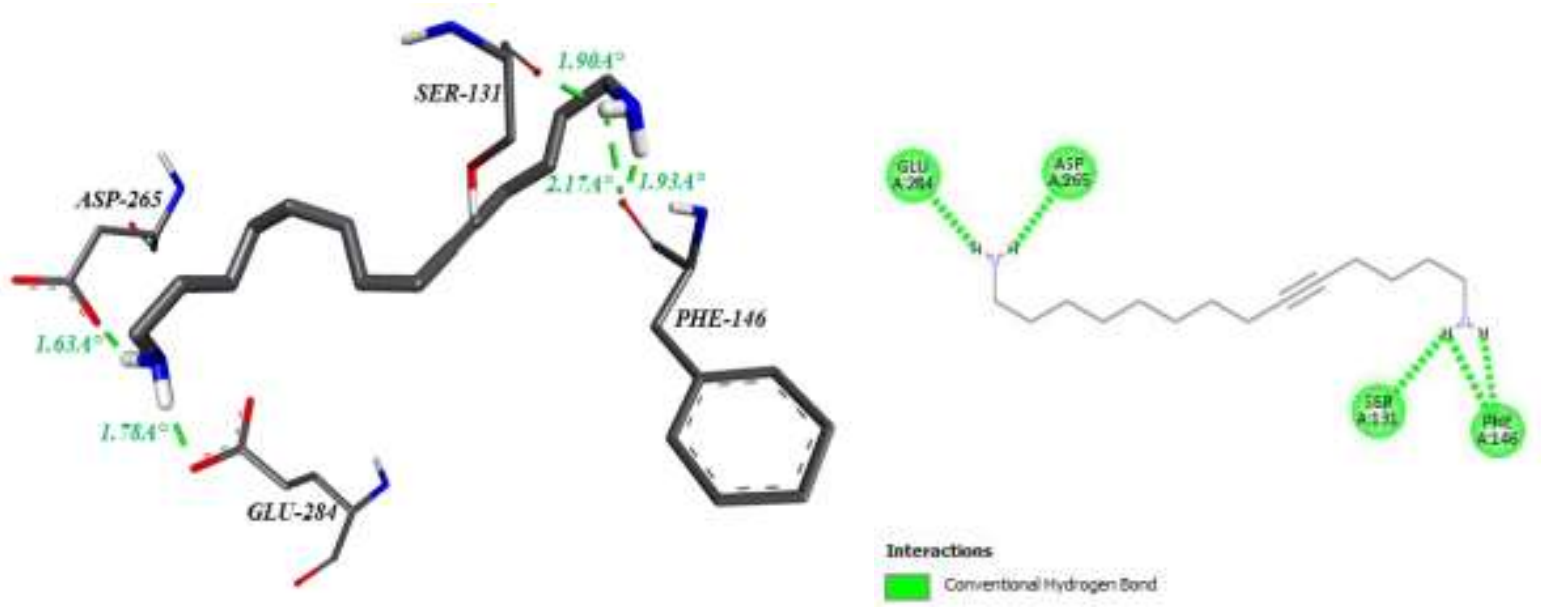

Figure 9. 2D and 3D maps of Molecular docking of compound 15 in the NMDA receptor NR2B subtype

Figure 10 illustrates the interactions of compound 2. One type of interaction is observed, $\pi$-sulfur with MET-132 $\left(\mathbf{4 . 2 1}^{\circ}\right)$ residue, however the amino groups did not form any interaction because of the alkylation of the $\mathrm{N}$ atom, which causes a drop in its biological activity.

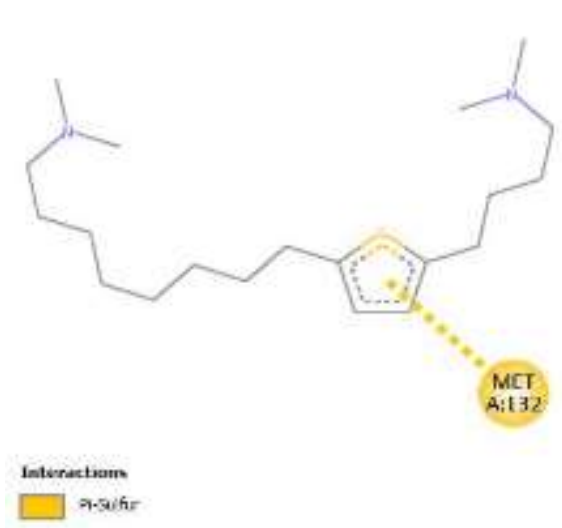

Figure 10. 2D and 3D maps of Molecular docking of compound 2 in the binding site of the NMDA receptor NR2B subtype

Figure 11 illustrates the interactions revealed with the docking of compound 35 to the NR2B subtype of NMDA receptor.
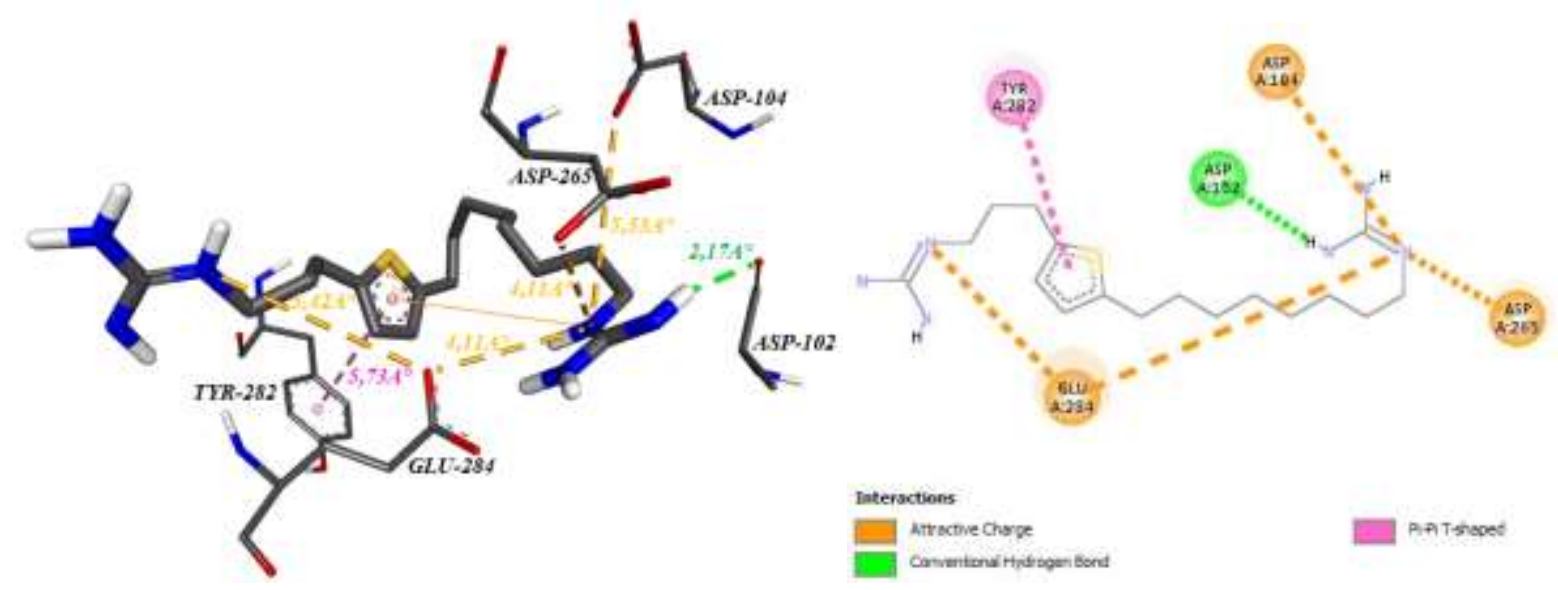

Figure 11. 2D and 3D maps of Molecular docking of compound 35 in the binding site of the NMDA receptor

As shown in Figure 11, compound 35 established four interactions $\pi$-cation throughout its two amino groups with important residues ASP-104 (5.53A $\left.{ }^{\circ}\right)$, ASP-265 $\left(\mathbf{4 . 1 1 A}^{\circ}\right)$, GLU-284 (4.11A $\left.{ }^{\circ}\right)$, and GLU-284 $\left(\mathbf{5 . 4 2}^{\circ}\right)$. One hydrogen bonding is formed with ASP$102\left(\mathbf{2 . 1 7}^{\circ}\right)$. Furthermore, the thiophene ring forms a $\pi-\pi$ T-shaped interaction with TYR-282(5.73A $\left.{ }^{\circ}\right)$ residue. 
From these results we can claim that the binding of ligands with NMDA receptor requires a hydrogen bonding throughout the two amino groups and an aromatic moiety as it is visualized in Figure 12. The alkylation of amino groups in compound 2 leads to a drop in biological activity and the absence of the aromatic group in compound 15 caused a concrete decrease in biological activity. Furthermore, the number of $\mathrm{N}$ atoms seems to play an essential role on biological activity potency; this is clear in compound

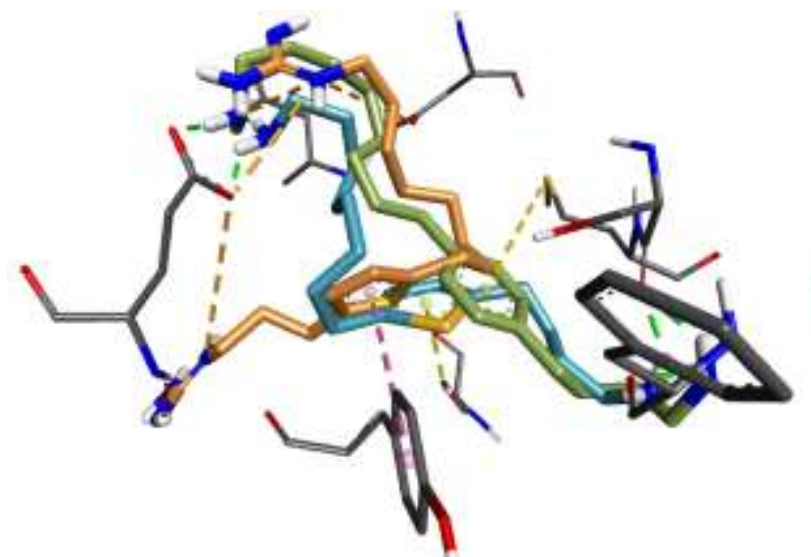

$35\left(\mathrm{pIC}_{50}=0.5068 \mu \mathrm{M}\right)$ which contains $6 \mathrm{~N}$ atoms compared to compound $1\left(\mathrm{pIC}_{50}=0.2065 \mu \mathrm{M}\right)$ which contains only $2 \mathrm{~N}$ atoms. We note that the number of $\mathrm{N}$ atoms is selected as a pertinent constitutional descriptor $\mathbf{n N}$ in QSAR model. Thus, essential selected descriptors forming the QSAR model are the same that are the most critical impact in molecular docking which reveals that nHBD the number of hydrogen bonding is a crucial factor in fixation with the binding sites.

Figure 12. Superimposition of the docked compounds 1,14 and 35 and visualization of the most important interactions formed with NR2B subtype of NMDA receptor

\section{Conclusion}

The statistical analysis that we have undertaken to establish a structure-activity relationship for the antagonists of the NMDA receptor showed that the activity of the Derivatives of 5-(4-aminobutyl)-2thiophene-octylamine is closely linked to the physicochemical descriptors. The compounds' activity correlates reasonably well with six descriptors selected by multiple linear regression (MLR) method. The correlation coefficients calculated by MLR and after that by $\mathrm{NN}, \mathbf{R}=\mathbf{0 . 8 7 8}$ and $\mathbf{R}=\mathbf{0 . 9 7 8}$ respectively, are reasonably competent to evaluate the quantitative model and to predict activity for new polyamine-sensitive inhibitors of the NMDA receptor. The CV test of the performance of the $\mathrm{NN}$ model $(\mathbf{R}=\mathbf{0 . 9 6 6})$ proved that the predictive power of this model is relevant. Furthermore, the molecular docking investigations revealed that the two amino groups and aromatic rings which establish hydrogen bonding or $\pi$-lone pair with the NR2B bindings represent the essential moieties in molecular structure for NMDA receptor antagonists. This is confirming the QSAR results that show that $\mathbf{n N}$ and $\mathbf{n H B D}$ are the most critical descriptors in QSAR model. These results could provide important structural insights needed to optimize new polyamine-sensitive inhibitors of the NMDA receptor.

\section{References}

1- S.F. Traynelis, L.P. Wollmuth, C.J. Mcbain, J. M. Chris, S.M. Frank, M.V. Katie, K.O. Kevin, B.H. Kasper, Y. Hongjie, J.M. Scott,
D. Ray, Glutamate receptor ion channels: structure, regulation, and function, Pharmacol. Rev., 2010, 62, 405-496.

2- S. Cull-Candy, S. Brickley, M. Farrant, NMDA receptor subunits: diversity, development and disease, Curr.Opin.Neurobiol., 2001, 11, 327-335.

3- S.F. Traynelis, M. Hartley, S.F. Heinemann, Control of proton sensitivity of the NMDA receptor by RNA splicing and polyamines, Sci., 1995, 26, 873-876.

4- K. Williams, C. Romano, P.B. Molinoff, Effects of polyamines on the binding of $\left[{ }^{3} \mathrm{H}\right] \mathrm{MK}-801$ to the N-methyl-D-aspartate receptor: pharmacological evidence for the existence of a polyamine recognition site, Mol.Pharmacol., 1989, 36, 575-581.

5- P. Thomas, S. Oliver, N. Daniela, R. Patrick, L.B. Michael, R.N. Christian, New polyaminesensitive inhibitors of the NMDA receptor: Syntheses and pharmacological evaluation, Eur. Jour. Medici. Chem., 2007, 42, 175-197.

6- H. Hadni, M. Mazigh, E. Charif, A. Bouayad, M. Elhallaoui, Molecular Modeling of Antimalarial Agents by 3D-QSAR Study and Molecular Docking of Two Hybrids 4-aminoquinoline-1,3,5-triazine and 4-amino-quinolineoxalamide Derivatives with the Receptor Protein in Its Both Wild and Mutant Types, Biochem. Res. Int., 2018, 1-15.

7- M.J. Frish, G. W. Turcks, H. B. Schlegel, G. E. Scuseria, M. A. Robb, J. R. Cheeseman, J. J. A. Montgomery, T. Vreven, K. N. Kudin, J. C. Burant, J. M. Millam, S. S. lyengar, J. Tomasi, 
V. Barone, B. Mennucci, M. Cossi, G. Scalmani, N. Rega, G.A. Petersson, H. Nakatsuji, M. Hada, M. Ehara, K. Toyota, R. Fukuda, J. Hasegawa, M. Ishida, T. Nakajima, Y. Honda, O. Kitao, H. Nakai, M. Klene, X. Li, J. E. Knox, H. P. Hratchian, J. B. Cross, V. Bakken, C. Adamo, J. Jaramillo, R. Gomperts, R. E. Stratmann, O. Yazyev, A. J. Austin, R. Cammi, C. Pomelli, J. W. Ochterski, P. Y. Ayala, K. Morokuma, G. A. Voth, P. Salvador, J. J. Dannenberg, V. G. Zakrzewski, S. Dapprich, A. D. Daniels, M. C. Strain, O. Farkas, D. K. Malick, A. D. Rabuck, K. Raghavachari, J. B. Foresman, J. V. Ortiz, Q. Cui, A. G. Baboul, S. Clifford, J. Cioslowski, B. B. Stefanov, G. Liu, A. Liashenko, P. Piskorz, I. Komaromi, R. L. Martin, D. J. Fox, T. Keith, M. A. Al-Laham, C. Y. Peng, A. Nanayakkara, M. Challacombe, P. M. W. Gill, B. Johnson, W. Chen, M. W. Wong, C. Gonzalez, J. Pople A. Revision D.01, Gaussian, Inc., Wallingford, CT, 2004.

8- R. Parr, W. Yang, Density Functional Theory of Atoms and Molecules, Oxf. Uni. Pre., New York, 1989.

9- A.D. Becke, «Density-Functional thermochemistry. III. The rol of exact exchange», J. Chem. Phys., 1993, 98, 5648.

10- ACD/ChemSketch Version 4.5 for Microsoft Windows User's Guide.

11- G. Saeed, G. Saeed, S. Ali, E.N. Heshmatollah, 2D-QSAR study of some 2,5-diaminobenzo- phenone farnesyltransferase inhibitors by different chemometric methods, ex.jour., 2015, 14, 484-495.

12- S. Mbarki, M. El Hallaoui, 3D-QSAR models to predict antimoebic activities of the cyclised pyrazolines and 2-(quinolin-8-yloxy) acetohydrazones, res.Jour.Phar.Bio.Chem.Sci., 2014, 5, 73-83.

13- S. So, G. Richards, Application of Neural Networks: Quantitative Structure-Activity Relationships of the Derivatives of 2,4-Diamino5- (substituted-benzyl) pyrimidines as DHFR Inhibitors. J. Med. Chem., 1992, 35, 3201-3207.

14- H. Hadni, M. Mazigh, M. Elhallaoui, QSAR and Molecular docking studies of 4-anilinoquinolinetriazine hybrids as pf-DHFR inhibitors, Mediterr. J. Chem., 2019, 8, 84-93.

15- G. Morris, R. Huey, AutoDock4 and AutoDockTools4: Automated docking with selective receptor flexibility, J. Comput. Chem., 2009, 30, 2785-2791.

16- Discovery Studio Visualizer v4.1.0.14169 Copyright (C) 2005-14, Accelrys Software Inc.

17- J. Rachline, F. Perin-Dureau, A.L. Goff, J. Neyton, P. Paoletti, The Micromolar ZincBinding Domain on the NMDA Receptor Subunit NR2B, Jour. Neu., 2005, 12, 308-317.

18- R.N. Rama, Molecular Modeling: A Powerful Tool for Drug Design and Molecular Docking, Res., 2004, 9, 51-60. 